\title{
Losartan-induced Severe Hepatic Injury: A Case Report and Literature Review
}

\author{
Ravikaran Patti ${ }^{1}$, Ankur Sinha ${ }^{2}$, Shaurya Sharma ${ }^{1}$, Taek Sang Yoon ${ }^{3}$, Yizhak Kupfer ${ }^{3}$ \\ 1. Internal Medicine, Maimonides Medical Center, Brooklyn, USA 2. Pulmonary and Critical Care, Maimonides Medical \\ Center, Brooklyn, USA 3. Critical Care, Maimonides Medical Center, Brooklyn, USA
}

Corresponding author: Ravikaran Patti, dr.ravikaran@gmail.com

\begin{abstract}
Medications have been known to cause adverse drug reactions that affect various organs; these are mostly reversible reactions that improve with the cessation of the culprit medication. Losartan is an angiotensinone receptor blocker which has been approved by the Food and Drug Administration (FDA) for the treatment of arterial hypertension. Fatigue, anemia, weakness, and cough are some of the common adverse effects of losartan. Acute hepatic injury has rarely been reported as an adverse effect of losartan. We report a case of a 61-year-old female with severe hepatic injury secondary to losartan use. None of the cases reported so far
\end{abstract} had such a high elevation of liver enzymes as seen in our patient.

Categories: Internal Medicine, Gastroenterology

Keywords: losartan, severe acute liver injury

\section{Introduction}

Losartan is an angiotensin two type one (AT1) receptor antagonist which has been approved for the management of arterial hypertension. Losartan is also used in diabetics to prevent renal damage, and in patients with heart failure with reduced ejection fraction. Commonly reported side effects of losartan are dry cough, hyperkalemia, and muscle cramps. Losartan-induced acute liver injury has rarely been reported. We report a case of acute fulminant liver injury due to losartan, which has never been reported before to the best of our knowledge.

Received 04/08/2019

Review began 04/16/2019 Review ended 05/21/2019 Published 05/28/2019

(c) Copyright 2019

Patti et al. This is an open access article distributed under the terms of the Creative Commons Attribution License CC-BY 3.0., which permits unrestricted use, distribution, and reproduction in any medium, provided the original author and source are credited.

\section{Case Presentation}

A 61-year-old woman with a history of hypertension, diabetes, and hypothyroidism presented to the emergency room with a high-grade fever, lethargy, and loss of appetite for the past couple of days. The patient had taken an over-the-counter Chinese cold preparation containing tylenol and diphenhydramine but without much relief. On the day of admission, she also vomited twice and was extremely dizzy. On initial presentation in the emergency room, the patient was febrile to $101.1^{\circ} \mathrm{F}$, respiratory rate was 18 breaths per minute, and blood pressure was 112/59 mm Hg. Blood work was significant for an abnormal liver profile with alanine transaminase (ALT) level of $1371 \mathrm{IU} / \mathrm{L}$ (normal 6-47 IU/L) and aspartate transaminase (AST) level of $1315 \mathrm{IU} / \mathrm{L}$ (normal 10-33 IU/L). Total and direct bilirubin was $0.7 \mathrm{mg} / \mathrm{dl}$ and $0.1 \mathrm{mg} / \mathrm{dl}$ respectively. Alkaline phosphatase (ALP) level of $75 \mathrm{IU} / \mathrm{L}$ was within normal limits. Computed tomographic (CT) scan of the abdomen and pelvis without oral or intravenous contrast revealed only mild hepatic steatosis as shown in Figure 1. 


\section{Cureus}



FIGURE 1: Computed tomographic scan of the abdomen showing mild hepatic steatosis

Due to elevated transaminitis, the patient was started on N-acetylcysteine (NAC) and liver function was closely monitored. All the home medications, including losartan and amlodipine, was held. On further blood work-up, serum amylase and lipase level were within the normal range, negative hepatitis panel (including A, $\mathrm{B}$, and $\mathrm{C}$ ), negative anti-mitochondrial and anti-smooth muscle antibodies and normal levels of serum alpha-one anti-trypsin and serum ceruloplasmin level. With ongoing treatment, the patient started improving clinically with down trending of AST and ALT level to $215 \mathrm{IU} / \mathrm{L}$ and $444 \mathrm{IU} / \mathrm{L}$, respectively. The trend of the patient's liver enzymes shown in Table 1.

\begin{tabular}{|c|c|c|c|c|}
\hline Liver enzymes & Day 1 & Day 2 & Day 3 & Day 4 \\
\hline ALT (IU/L) & 1,371 & 958 & 479 & 444 \\
\hline AST (IU/L) & 1,315 & 831 & 308 & 215 \\
\hline ALP (IU/L) & 75 & 65 & 80 & 101 \\
\hline Total Bilirubin (mg/dl) & 0.7 & 0.4 & 0.3 & 0.3 \\
\hline
\end{tabular}

\section{TABLE 1: Course of patient's liver enzymes}

ALT: Alanine transaminase; AST: Aspartate transaminase; ALP: Alkaline phosphatase

The patient was discharged on day five, with down-trending of the liver enzymes. Losartan was among the differentials of the acute liver insult and the patient and the family were counseled to refrain from its further use.

The patient was brought back to the emergency room two days later with severe lethargy vomiting. Laboratory work-up showed ALT 3444 IU/L and AST 5232 IU/L. On further questioning, the patient's family mentioned that they gave two doses of $100 \mathrm{mg}$ of losartan. NAC was immediately initiated and losartan was stopped on readmission. Over the course of a few days in the hospital, liver enzymes started trending down as shown in Table 2. 


\section{Cureus}

\begin{tabular}{|c|c|c|c|c|}
\hline Liver enzymes & Day 1 & Day 2 & Day 3 & Day 4 \\
\hline ALT (IU/L) & 2,838 & 3,444 & 4,137 & 2,855 \\
\hline AST (IU/L) & 3,600 & 5,232 & 5,677 & 2,905 \\
\hline ALP (IU/L) & 161 & 62 & 161 & 133 \\
\hline Total bilirubin (mg/dl) & 0.7 & 1.2 & 2.5 & 3.0 \\
\hline
\end{tabular}

TABLE 2: Course of patient's liver enzymes on re-admission

ALT: alanine transaminase; AST: aspartate transaminase; ALP: alkaline phosphatase

The patient and the family were counseled to strictly refrain from any more use of losartan.

\section{Discussion}

Losartan is a competitive antagonist and blocks angiotensin-one receptors. In 1995, the Food and Drug Administration (FDA) approved losartan for the treatment of arterial hypertension [1]. It was also approved for reducing risks of cerebrovascular accidents in patients with hypertension or left ventricular hypertrophy, and for slowing the progression of diabetic nephropathy by improving proteinuria [1]. Losartan has been studied extensively for the management of the aforementioned conditions. Losartan also has had a modest uricosuric effect and is used as a first-line agent for managing hypertension in patients with gout.

The oral bioavailability of losartan is around $33 \%$ and it has a great first-pass metabolism [2]. Cytochrome P450 enzymes, CYP2C9 and CYP3A4, are involved in activating losartan to its active metabolite [2]. Losartan is mainly eliminated through feces and urine. The half-life of losartan is around two hours while the terminal half-life of its active metabolites is around six to nine hours.

Drug-induced adverse reactions have been reported since the advent of the medication. Many drugs have been known to cause acute liver injury, and it has been labelled as one of the prime causes of liver failure in the country, requiring liver transplantation in over $75 \%$ of these patients [3]. The incidence of drug-induced liver injury (DILI) is around one to two cases per 1,00,000 person-years in the general population [4]. Abnormalities in the liver enzymes, especially alanine transaminase (ALT), aspartate transaminase (AST), alkaline phosphatase (ALP), gamma-glutamyl transpeptidase (GGT), and total and direct bilirubin are important tools for diagnosing a patient with DILI. Patients usually complain of malaise and jaundice upon initial presentation. Drug-induced liver injury can be hepatocellular, cholestatic, or mixed. Hepatocellular injury can result in a marked elevation of only the aminotransferases without significantly affecting the ALP or the total or direct bilirubin, while in cholestatic injury, the ALP is mainly affected and rises disproportionately to AST/ALT. In a mixed pattern, usually, a mixture of both the hepatocellular and cholestatic injury is observed. The ' $\mathrm{R}$ ratio', which is the ratio of serum ALT to serum ALP results with respect to their upper limits of normal (ULN), can also be used to label the type of liver injury [4]. An R ratio of five or more implies hepatocellular injury, two or lesser points towards cholestatic damage and values between two to five are labelled as mixed [4]. The use of the $\mathrm{R}$ ratio is often advised at the initial presentation. Liver biopsy is the gold standard for accurately classifying the type of injury. The results of the liver biopsy may vary with the timing of the biopsy as hepatocellular damage is more pronounced in the initial days/weeks while cholestatic damage becomes evident a little later [4].

To the best of our knowledge, 18 cases of angiotensin receptor blocker causing liver injury has been reported. Out of those, six cases were due to losartan, five were with Irbesartan, four with candesartan, and three cases were due to valsartan use as listed in Table 3 [1,5-10]. 


\begin{tabular}{|c|c|c|c|c|c|c|c|}
\hline Case & Age/Sex & Drug/dose & Timing & AST (IU/L) & ALT (IU/L) & Re-exposure & Biopsy \\
\hline 1. & 65 female & Losartan $50 \mathrm{mg}$ & 4 months & 1,018 & 1,184 & No & No \\
\hline 2. & 46 male & Losartan $50 \mathrm{mg}$ & 1 month & 2,042 & 2,547 & No & No \\
\hline 3. & 46 female & Losartan $50 \mathrm{mg}$ & 3 months & 300 & 311 & No & No \\
\hline 4. & 55 female & Losartan $50 \mathrm{mg}$ & 3 weeks & 635 & 650 & No & No \\
\hline 5. & 52 female & Losartan $50 \mathrm{mg}$ & 5 months & 1,093 & 941 & Yes & Yes \\
\hline 6. & 77 male & Losartan $150 \mathrm{mg}$ & 3 weeks & 115 & 410 & No & Yes \\
\hline 7. & 69 male & Irbesartan $300 \mathrm{mg}$ & 1 month & 821 & 1,449 & No & Yes \\
\hline 8. & $59 \mathrm{NA}$ & Irbesartan 300 mg & 20 days & 1,347 & 1,378 & No & No \\
\hline 9. & 51 female & Irbesartan $150 \mathrm{mg}$ & 3 weeks & 237 & 890 & No & No \\
\hline 10. & 62 female & Irbesartan 300 mg & 1 month & 177 & NA & No & Yes \\
\hline 11. & 56 male & Irbesartan 300 mg & 8 days & 1,438 & 2,646 & No & Yes \\
\hline 12. & 41 female & Candesartan $16 \mathrm{mg}$ & 6 months & 1,600 & 2,700 & No & No \\
\hline 13. & 61 female & Candesartan 16 mg & 1 month & 1,367 & 918 & No & Yes \\
\hline 14. & 82 male & Candesartan 16 mg & 3 weeks & 111 & 272 & No & No \\
\hline 15. & 70 female & Candesartan NA & 2 weeks & 441 & 244 & No & No \\
\hline 16. & 52 female & Valsartan NA & 1 month & 1292 & 780 & No & No \\
\hline 17. & 54 female & Valsartan $80 \mathrm{mg}$ & 5 months & 738 & 1,664 & No & Yes \\
\hline 18. & 47 male & Valsartan $80 \mathrm{mg}$ & 2 weeks & 360 & 776 & No & No \\
\hline OUR CASE & 61 female & Losartan $100 \mathrm{mg}$ & 16 days & 5,677 & 4,137 & Yes & No \\
\hline
\end{tabular}

TABLE 3: All reported cases of liver injury due to angiotensin receptor blockers

ALT: alanine transaminase; AST: aspartate transaminase

Although hepatocellular injury was the most common type of damage in the cases reported, cholestatic as well as mixed injury patterns were observed as well.

We are reporting the seventh case of losartan-associated severe liver injury. Our patient also had hepatocellular injury as was evident by the elevated transaminases to around 30 times the upper limit of the normal range without any increase in serum ALP or bilirubin. Upon subsequent presentation 48 hours later, our patient was noted to be very lethargic. The family had mentioned that the patient took two doses of losartan $100 \mathrm{mg}$; the liver enzymes were found to be elevated to around 75-100 times the upper limit of the normal range with AST of 5,677 IU/L and ALT of 4,137 IU/L. This degree of elevation has never been reported before to the best of our knowledge. As per the Naranjo algorithm, the event scored a nine, which solidifies losartan as the 'definite cause' of acute liver injury. The usual cause of such high elevation in aminotransferases is shock liver. Other causes like viral hepatitis, tylenol toxicity, biliary blockage, and sepsis should also be ruled out. Disorders like Wilson's disease, hemochromatosis, and autoimmune hepatitis can also lead to an elevation in aminotransferases.

Stopping the offending agent should be the first step as soon as the drug has been labelled as the cause of liver injury. $\mathrm{N}$-acetyl cysteine can be used if the aminotransferase has been dangerously high or is not trending down. Usually, the improvement in the liver enzymes happen within hours to days but in a minority of patients, the liver damage progresses to necessitate liver transplantation. The degree of liver injury is usually worse when the patient is re-exposed to the same drug. The patient should be strictly counseled to not use the drug again.

\section{Conclusions}

Losartan and other angiotensin receptor blockers have very rarely been reported to cause acute liver injury. By reporting this case, we aim to increase awareness among physicians to always rule out losartan as a cause 
of unexplained elevation in aminotransferases. We also want to emphasize that once these drugs have been found to be the causative agent for the insult, patients should be strictly counselled not to use them again, as the acute liver injury may advance unto the need for liver transplantation.

\section{Additional Information \\ Disclosures}

Human subjects: Consent was obtained by all participants in this study. Conflicts of interest: In compliance with the ICMJE uniform disclosure form, all authors declare the following: Payment/services info: All authors have declared that no financial support was received from any organization for the submitted work. Financial relationships: All authors have declared that they have no financial relationships at present or within the previous three years with any organizations that might have an interest in the submitted work. Other relationships: All authors have declared that there are no other relationships or activities that could appear to have influenced the submitted work.

\section{References}

1. Moh'd ZAH, Thawabi M, Asslo F, Shaaban H, Shamoon F, Baddoura WJ: Losartan-induced ischemic hepatocellular hepatotoxicity: a case report and literature review. J Family Med Prim Care. 2014, 3:272-274. 10.4103/2249-4863.141635

2. Ripley E, Hirsch A: Fifteen years of losartan: what have we learned about losartan that can benefit chronic kidney disease patients?. Int J Nephrol Renovasc Dis. 2010, 3:93-98. 10.2147/IJNRD.S7038

3. Lee, WM: Drug-induced hepatotoxicity. N Engl J Med. 2003, 349:474-485. 10.1056/NEJMra021844

4. Fontana R J, Seeff L B, Andrade RJ, et al.: Standardization of nomenclature and causality assessment in drug-induced liver injury: summary of a clinical research workshop. Hepatology. 2010, 52:730-742.

5. Nygaard B, Strandgaard S: Marked hepatotoxicity associated with losartan treatment . Blood Press. 1996, 5:190-191. 10.3109/08037059609062128

6. Bosch X: Losartan-induced hepatotoxicity. JAMA. 1997, 278:1572. 10.1001/jama.278.19.1572

7. Tabak F, Mert A, Ozaras R, et al.: Losartan-induced hepatic injury. J Clin Gastroenterol. 2002, 34:585-586. 10.1097/00004836-200205000-00022

8. Andrade RJ, Lucena MI, Santalla F: Hepatic injury associated with losartan. Ann Pharmacother. 1998, 32:1371. 10.1345/aph.18087a

9. Hariraj R, Stoner E, Jader S, Preston DM: Drug points: prolonged cholestasis associated with irbesartan . BMJ. 2000, 321:547. 10.1136/bmj.321.7260.547

10. Andrade RJ, Lucena MI, Fernández MC, et al.: Cholestatic hepatitis related to use of irbesartan: a case report and a literature review of angiotensin II antagonist-associated hepatotoxicity. Eur J Gastroenterol Hepatol. 2002, 14:887-890. 10.1097/00042737-200208000-00014 